\title{
Processo de escolarização e a formação de uma elite letrada no Brasil: o caso da província de Sergipe d’El Rey
}

\author{
Fábio Alves dos Santos \\ Universidade Federal de Sergipe - SE, Brasil. \\ fabbioallves@gmail.com
}

Educação: teoria e prática, Rio Claro, SP, Brasil - elSSN: 1981-8106

Está licenciada sob Licença Creative Common

\section{Resumo}

A presente proposta de artigo faz parte de uma pesquisa que investe sobre a relação entre o ofício docente e a elite letrada, no Brasil do século XIX. No geral, o referido estudo visa identificar e analisar o capital necessário para o exercício da docência no século XIX, com foco privilegiado sobre o Ensino Secundário, mas não só. Toma como lócus de observação, para tanto, a província de Sergipe d'El Rey. Neste extrato, o objetivo é descrever e analisar os processos formativos e as formas de entrada no ofício docente. Para realização desta empreitada, foi realizado um levantamento de dados no Dicionário Bio-Bibliográfico Armindo Guaraná, em que foi possível identificar cento e trinta e quatro professores, dos quais três mulheres. O procedimento permitiu identificar um grupo de professores de Sergipe, no século XIX, com destaque para o Ensino Secundário, e analisar suas trajetórias de formação e experiências no campo da docência. Constatou-se que é possível investir contra a tese recorrente de que a elite brasileira do século XIX era formada essencialmente por bacharéis em Direito. Percebeu-se que o traço efetivamente distintivo e homogeneizador deste era o Ensino Secundário, completo ou na forma dos famigerados preparatórios.

Palavras-chave: Escolarização. Cultura Escolar. Elite Letrada. Ensino Secundário.

Sergipe.

\section{Schooling process and the formation of a literary elite in Brazil: the case of the province of Sergipe D'El Rey}

\begin{abstract}
The proposed article is part of a research that invests on the relationship between the teaching occupation and the literary elite in nineteenth-century Brazil. Overall, this study aims to identify and analyze the capital required to teach in the nineteenth century, with prime focus on secondary education, but not only. Takes as its locus of observation, for both the province of Sergipe d'El Rey. In this extract, the goal is to describe and analyze the formative processes and ways of entering the teaching
\end{abstract}


occupation. To perform this task, a data collection was performed in BioBibliographical Dictionary Armindo Guaraná, it was possible to identify one hundred thirty-four teachers, including three women. The procedure identified a group of professors in Sergipe, in the nineteenth century, with emphasis on Secondary Education, and analyze their trajectories training and experience in the field of teaching. It was found that it is possible to invest against the applicant thesis that the Brazilian elite of the nineteenth century was essentially formed by graduates in law. It was noticed that the distinctive trait effectively homogenizer and this was secondary education, in the form of full or preparatory notorious.

Keywords: Schooling. School Culture. Literary Elite. Secondary Education. Sergipe.

\section{Proceso de escolarización y la formación de una elite letrada en Brasil: el caso de la provincia de Sergipe d'El Rey}

\section{Resumen}

La presente propuesta de artículo forma parte de una investigación que invierte en la relación entre el oficio docente y la elite letrada, en el Brasil del siglo XIX. En general, el referido estudio tiene como objetivo identificar y analizar el capital necesario para el ejercicio de la docencia en el siglo XIX, con foco privilegiado sobre la Enseñanza Secundaria, pero no solo eso. Toma como locus de observación, para esto, la provincia de Sergipe d'El Rey. En este extracto, el objetivo es describir y analizar los procesos formativos y las formas de entrada en el oficio docente. Para la realización de esta empresa, se realizó un levantamiento de datos en el Dicionário Bio-Bibliográfico Armindo Guaraná, en el que fue posible identificar ciento treinta y cuatro profesores, de los cuales tres son mujeres. El procedimiento permitió identificar un grupo de profesores de Sergipe, en el siglo XIX, con destaque para la Enseñanza Secundaria, y analizar sus trayectorias de formación y experiencias en el campo de la docencia. Se constató que es posible trabajar contra la tesis recurrente de que la elite brasileña del siglo XIX estaba formada esencialmente por licenciados ${ }^{1}$ en Derecho. Se percibió que el trazo efectivamente distintivo y homogeneizador de este era la Enseñanza Secundaria, completa o en la forma de los famosos preparatorios.

Palabras clave: Escolarización. Cultura Escolar. Elite Letrada. Enseñanza Secundaria. Sergipe.

A formação escolar dos membros da elite sergipana, que em algum momento de suas vidas se dedicaram à docência, tinha no Ensino Secundário, certamente, seu locus fundamental. Como nem todos eles chegaram a cursar uma das formas de

\footnotetext{
${ }^{1}$ el término originalmente usado es bacharelados. En Brasil, la enseñanza universitaria ofrece dos tipos de títulos: a) bacharelado: el estudiante recibe una formación para actuar de manera amplia en el mercado;

b) licenciatura: esta titulación está destinada a los estudiantes que, además de una formación, pretenden impartir clases en escuelas de educación básica hasta bachillerato.
} 
estudos superiores (algo já apontado pela pesquisa de SILVA, 2004), o Secundário figura como o tipo de escolarização comum ao grupo.

Muitas leituras acerca da escolarização no século XIX têm dificuldade em entender o modo de funcionamento próprio daquele período, e consideram como insuficiências da escola oitocentista a ausência de características que só seriam hegemônicas no século XX, em muitos casos com a centúria já bem avançada. Esse é o caso da interpretação de Nunes (1984) acerca da relação entre a oferta pública e privada e sua procura pela população. No seu entendimento, partilhado por autores que inclusive se dizem membros de uma proposta de releitura hodierna da História, a escola carecia de interesse do poder público, o que teria como uma das consequências a preferência da população pelas aulas ou colégios particulares.

\section{Alguns elementos para compreender o Ensino Secundário}

Uma das conclusões da pesquisa da qual este artigo se origina ${ }^{2}$ é que o lugar de formação escolar comum aos diferentes sujeitos aqui analisados foi o Ensino Secundário. Embora muitos deles tenham concluído um dos cursos superiores disponíveis em seu tempo, ter passado por aquele tipo de ensino, em qualquer de suas variações, foi elemento chave para sua atuação social e sua identificação, ao menos para fins deste estudo, como pertencentes a uma elite letrada, ou seja, sujeitos que possuíam uma formação escolar restrita a poucos e que lhes possibilitava almejar determinados lugares sociais.

O Ensino Secundário é aqui entendido como um tipo de ensino, dentre outros existentes no século XIX, que não estava ao alcance de todos, nem a todos era destinado, mas que não era exclusivo de uma elite econômica, uma vez que recebeu, em seus bancos escolares, indivíduos oriundos não das camadas sociais mais desvalidas, obviamente, mas de extratos intermediários, que a ele tiveram acesso, em muitos casos, por meio da rede de sociabilidade na qual estavam inseridos.

Desse modo, o Ensino Secundário não deve ser confundido, embora o seja frequentemente, como o antepassado do Ensino Médio hodierno, de tempos de ENEM. Não se constituía, àquela época, uma etapa obrigatória da escolarização das pessoas (ao fim e ao cabo nenhum dos tipos existentes era, ainda, de fato obrigatório, visto que as ferramentas da obrigatoriedade efetiva não estavam firmadas, embora já fossem existentes para o caso da escola elementar).

\footnotetext{
${ }^{2}$ Este artigo se origina de minha pesquisa de doutoramento, realizada no Programa de Pós-Graduação em Educação da Universidade Federal de Sergipe sob a orientação da Prof. Dra. Eva Maria Siqueira Alves, que visa analisar a relação entre a elite letrada sergipana e o ofício docente, a partir das biografias constantes no Dicionário Bio-Bibliográfico Armindo Guaraná.
} 
Sequer era obrigatória a conclusão do Secundário em sua totalidade. Era possível cursar disciplinas (se é que se pode usar este termo com exatidão para os Oitocentos) em isolado, nos conhecidos Cursos de Preparatórios, restringindo-se às matérias de estudos exigidas nos exames das faculdades existentes, ou nem isso. Se isso é verdade, o mesmo não pode ser dito acerca da interpretação de que essa era a norma geral. É sabido que houve quem concluísse o curso completo, como estava previsto, e fazê-lo garantia alguma possibilidade de vantagem no concorrido mercado de trabalho da época (sim, concorrido, uma vez que outro equívoco que fica evidente é afirmar que os membros desse grupo que detinha um grau de formação escolar maior estavam com todas as garantias de sucesso em suas trajetórias de vida).

Seja como for, com o Ensino Secundário completo ou em sua variante dos preparatórios, ou mesmo concluindo um dos cursos superiores, era no Secundário que acontecia uma formação comum a esse grupo, que corta transversalmente suas trajetórias escolares, independente de sua completude ou consecução. O secundário caracterizava-se como traço distintivo do grupamento social aqui analisado. Cabe compreendê-lo um pouco melhor.

Há estudos já clássicos sobre o Ensino Secundário no Brasil ${ }^{3}$. Para o caso do século XIX, certamente o texto de Haidar (2008), publicado originalmente em 1972, é o mais representativo. Nesse estudo, Haidar trabalha para confirmar a hipótese de que o Secundário, no Brasil do século XIX, não obteve sucesso devido à presença dos exames parcelados de preparatórios. Tais exames garantiam, de fato, a possibilidade de acesso a um dos cursos superiores existentes à época.

No geral, o quadro pintado acerca do Ensino Secundário por Haidar não é dos mais animadores. Dentre as várias informações que se pode acessar nessa leitura, pode-se saber que o Ato Adicional de 1834 dividiu as responsabilidades no que diz respeito à oferta pública de educação, ao conferir às províncias o direito de legislar sobre instrução pública e estabelecimentos próprios a promovê-la. Segundo a autora, foi a partir de 1834 que se efetivaram as primeiras providências para garantir alguma organização aos estudos públicos secundários, que, à época, fragmentavam-se no modelo das aulas régias instituídas pela Reforma Pombalina.

Essa organização teria sido prejudicada por diversos fatores, dos quais (além dos já citados Exames de Preparatórios) a instabilidade dos presidentes provinciais que se sucediam, às vezes, à razão de dois ou mais por ano, o que gerava, na visão de vários estudiosos, uma descontinuidade administrativa. Somava-se a isso a

\footnotetext{
${ }^{3}$ Muitos estudos foram desenvolvidos sobre o tema a partir dos anos 1960, devido ao aumento tanto da demanda quanto da oferta, além da reformulação do Ensino Secundário que esse movimento expansionista demandava. Ver, a título de exemplo, o estudo de João Batista Borges Pereira (1969), "A escola secundária numa sociedade em mudança", sobre a implantação de uma escola secundária na periferia da cidade de São Paulo.
} 
precariedade financeira da maioria das províncias. Mas, o mais grave seria o não reconhecimento das aprovações conferidas pelos liceus provinciais para fins de matrículas nos cursos superiores disponíveis.

A partir desses elementos, Haidar (2008) formula a tese da pseudodescentralização dos estudos secundários, uma vez que apenas os candidatos egressos do Colégio Pedro II teriam acesso garantido às academias. Isso desestimularia, nas províncias, a conclusão do Ensino Secundário e, por consequência, favoreceria a procura pelos cursos de Preparatórios e os exames parcelados. Com o fortalecimento dessa prática, outros problemas teriam se agregado.

De um lado, professores públicos, que a despeito dos regulamentos sobre o ofício, ministravam aulas particulares das disciplinas exigidas nos exames. Por outro, a proliferação de instituições de ensino particular que ofereciam em sua grade de estudos apenas os saberes exigidos pelos exames. De acordo com Haidar, essa situação fez com que os liceus mantidos pelo poder público entrassem em decadência e o Ensino Secundário nas províncias fosse oferecido quase exclusivamente pela iniciativa privada.

No que diz respeito ao Colégio Pedro II, Haidar (2008) afirma que foi a única instituição pública de Ensino Secundário na Capital durante o Império e que, apesar de no plano ideal ter sido pensado e organizado para servir de padrão a todas as instituições congêneres pelo território brasileiro, o padrão real foi estabelecido pelos preparatórios e exames parcelados.

Ainda em relação à iniciativa privada, Haidar informa que devido à precária fiscalização das autoridades e à propagação da teoria do ensino livre, a partir de meados da década de 1860 os estabelecimentos particulares, em todo o Brasil, estavam ramificados. Na perspectiva da autora, isto era mais um problema para o fortalecimento do Ensino Secundário. Isso porque, salvo raras exceções (escolas particulares que propunham um curso completo), a maioria delas funcionava oferecendo apenas os saberes exigidos nos exames prestados junto às Faculdades.

Essa perspectiva interpretativa não difere muito de outra leitura sobre o Ensino Secundário no Brasil do século XIX, bastante difundida. Trata-se do texto de Azevedo (1976), que serviu de base a várias interpretações futuras. Em sua escrita, Azevedo apresenta os anos Oitocentos como um período marcado pela desorganização, pouca ação do poder público e desenvolvimento da iniciativa privada. Aspecto que, talvez, desvele a maior discordância entre Haidar (2008) e Azevedo (1976), uma vez que este entende ter sido positiva a ação das instituições particulares e delas terem surgido os melhores resultados no que diz respeito à formação da elite letrada brasileira.

Ambos concordam com o papel de destaque do Colégio Pedro II, embora Azevedo não se detenha ao fato de poucos alunos concluírem o curso proposto ali em 
sua completude, como faz Haidar. Seja como for, Haidar e Azevedo concordam com a tese de que o Ato Adicional, ao transferir para as assembleias provinciais os poderes sobre a instrução pública elementar e secundária, trouxe prejuízos para o desenvolvimento harmônico do ensino no Brasil de modo geral.

Elitista. Aristocrático. Desinteressado. Fracassado. A leitura de textos fundantes acerca do entendimento sobre o Ensino Secundário no Brasil do século XIX conduz à sua rápida compreensão nesses termos. Cópia mal sucedida de experiências estrangeiras, principalmente do caso francês, mal adaptado às particularidades da realidade brasileira. Espaço de especulação da indústria escolar, meio de enriquecimento de alguns. Todavia, a investida em estudos que se dedicaram a compreender o Secundário no mundo Ocidental, particularmente na Europa, propicia uma outra perspectiva interpretativa.

Quando surgiu o Ensino Secundário? Essa pergunta foi respondida (ao menos para o caso francês) por Chervel (1992) em um artigo homônimo, e é bastante revelador da situação do Secundário na França, nos Oitocentos. Entender essa situação contribui para um mínimo questionamento acerca das influências, das escolhas equivocadas, dos desarranjos aos quais foi supostamente submetido o Secundário no Brasil.

Segundo Chervel, foi aproximadamente em 1815 que se empregou, pela primeira vez, o termo secundário no sentido moderno para se referir, na França, a todos os estabelecimentos tipificados como liceu ou colégio. Além disso, as fases da Revolução e do Império não criaram escolas secundárias do Estado. O ensino de tipo secundário teria, então, sua gênese na ação das congregações religiosas que perderam suas instituições educacionais com os eventos de 1789, e reviveram estabelecimentos intermediários entre a instrução primária e a universidade, muito comuns no século XVIII, como escolas latinas, regências latinas, pedagogias, seminários e pequenos colégios, que passaram a ser chamados de escolas secundárias.

O sucesso desse tipo escolar fez com que o Consulado e o Império, a fim de preservar os liceus, criassem mecanismos de controle sobre aqueles estabelecimentos novos. Apesar de, por volta de 1808 , a definição escola secundária ter desaparecido dos textos oficiais, na linguagem comum o termo já estava firmado e positivamente reconhecido, não obstante nessas escolas o ensino limitar-se às classes de gramática e chegar, quando muito, à classe final do ginasial.

A difusão e aceitação da escola secundária e a preocupação oficial em normatizá-la de alguma forma têm sua explicação no debate acerca das relações entre a instrução primária e o ensino superior. Segundo Chervel (1992), desde o final do Antigo Regime, na França, estava posto o problema: o ensino elementar deveria ou 
não ser pensado como preparatório aos cursos superiores, mesmo sabendo-se que a maioria dos alunos não passaria do primário?

Em resposta, ao longo da primeira metade dos Oitocentos firmou-se o entendimento de que o ensino primário constituía-se em um conjunto fechado em si mesmo, que deveria haver dois sistemas completos de instrução que nada possuíssem em comum. Visando estabelecer tal demarcação, o governo de Napoleão, ao reformar os estatutos da Universidade francesa, estabeleceu um duplo imposto sobre professores e alunos e essa cobrança, que não se aplicava às escolas primárias, criou a unidade entre as instituições que davam acesso ao ensino superior. A esse conjunto de estabelecimentos educacionais atribuiu-se, então, o nome Ensino Secundário.

Ainda, em acordo com Chervel, a base da cobrança tributária se deu sobre o ensino de certas disciplinas, destacadamente de uma: o Latim. Segundo o autor, na realidade o Latim foi a única discriminação efetiva entre o primário, livre da taxação, e o secundário. A tributação só foi extinta em 1844. O evento da tributação promoveu uma mudança de hábitos na rede escolar francesa. Se, no início do século XIX, várias escolas procuraram se beneficiar junto ao público com o título de escola secundária, a partir da criação do imposto várias delas, ao ver seu contingente de alunos diminuir, optaram por retirar o Latim de sua grade de estudos. O poder público conseguiu, assim, conter a expansão daquele tipo de escolas e estabelecer uma linha distintiva de acesso à universidade.

Esse movimento regulatório garantiu um dos princípios do pós-Revolução. A função da instrução era garantir a ordem social. Para efetivar esse plano, tornara-se imprescindível distinguir dois tipos de instrução: a primária, ramificada por todo o território, educação de massa, apoiada em metodologias que garantissem o maior número de atendimento possível; e uma outra, destinada às classes mais abastadas, cujo objetivo seria garantir a transmissão da cultura de classe média. A taxação sobre o ensino de Latim controlava, e, assim, contribuía com o plano, a quantidade de alunos que chegavam aos chamados estudos clássicos.

Chervel (1992) destaca que, a partir dessas regulamentações, o adjetivo secundário ganhou nova conotação e passou-se a falar menos em escola secundária e mais em instrução, ensino e estudos secundários. Esse entendimento ganhou força a partir da década de 1830, quando se definiu ainda mais que um ensino sem Latim não seria secundário, seria apenas primário. A instrução primária foi reformulada, à época, mas não com a inclusão daquela disciplina. O que se fez foi criar as escolas primárias superiores, mantendo o espaço distintivo do ensino secundário.

Para o autor francês, a adoção pela linguagem corrente do termo ensino secundário pode ser considerada, assim, tardia. Ocorreu por volta de 1845 . Isso pode ser percebido, observando a inclusão do termo no sentido moderno pelos dicionários. 
O ensino secundário é, por definição corrente, de classe e elitista, controlado pelo Estado, destinado àqueles que poderão cursar uma universidade. Ainda que os alunos egressos do secundário não chegassem ao ensino superior, seu traço distintivo já estava estabelecido, uma vez que poucos tinham condições de cursá-lo.

Por fim, ressalte-se que o perfil formativo do Secundário na França passou por mudanças apenas no início do século XX. O currículo conhecido como clássico, enciclopédico, de formação pouco pragmática e desinteressada passou a ser questionado. Em seu lugar foi pensada uma formação mais científica e destinada a um público mais abrangente. Passou, então, a constituir um segundo grau de ensino, dentro de uma escala formativa, e não mais como um tipo destinado a uma camada da sociedade. Mas esse não era o perfil do secundário francês no século XIX.

Um olhar mais ampliado sobre o ensino secundário na Europa dos Oitocentos possibilita compreender ainda melhor tais questões. Isso é o que proporciona a leitura do artigo de Anderson (2004). Para ele, as principais características do modelo Lycée (francês) e Gymnasiun (alemão) - tomados como as principais referências institucionais no período - podem ser assim resumidas: tratava-se de instituição pública, laica, administrada pelo Estado ou pelas autoridades locais; constituíam uma educação de elite com pouca conexão orgânica com a educação popular; uma de suas funções, muitas vezes vista como a principal, era preparar para a entrada no ensino superior; um currículo predominantemente clássico, com destaque para o ensino de Latim e Grego (mais aquele do que este); ministrado por professores especialistas formados nas universidades, professores que, selecionados pelo Estado, procuravam compartilhar seus valores acadêmicos e científicos; e com uma duração entre oito ou nove anos que culminava em um exame (o baccalauréat francês, o abitur alemão) que definia a conclusão dos estudos secundários.

Essas definições gerais, segundo Anderson (2004), produzem um entendimento equivocado sobre o ensino secundário. Não que os elementos listados não caracterizem bem esse tipo de ensino. Pelo contrário, constituem uma boa síntese. 0 problema seria pensar que o modelo surgiu pronto e acabado, ou mesmo que sua aceitação foi imediata e que com esses contornos se estabeleceu em todos os países (pode-se pensar na sempre lembrada expressão influência, por exemplo).

O Ensino Secundário é uma invenção do século XIX, isso é fato. Durante aquela centúria, foi ajustado a diferentes configurações sociais. Segundo Robert Anderson, a nova relação entre o ensino secundário e as universidades de forma definitiva foi tardia em muitos países. Além disso, o termo secundário foi usado em diferentes sentidos, e com limites diversos. De um lado, as universidades que tinham definido as formas de instrução geral e preparatória, definida como secundário, e que às escolas caberia desenvolver. De outro (como na Baviera, Áustria, Holanda e Inglaterra), viu-se 
o desenvolvimento de instituições intermediárias pensadas dentro de um sistema que interligava o ensino secundário e o superior.

Geralmente, a assimilação ao novo padrão fazia-se acompanhar da adoção do ideal universitário humboldtiano (que pensava a universidade não apenas como local de ensino, mas, também, de pesquisa), e ocorreu principalmente entre 1848 e 1870, chegando, em alguns casos, até a década de 1890. Junte-se a esses elementos a aceitação de 18/19 anos como uma idade natural de transição entre o secundário e a universidade, fato que está claramente relacionado com a história social da adolescência (como outras fases da vida, a adolescência é uma construção social).

A existência de uma rede de escolas do tipo Secundário, muitas vezes como parte das estruturas do Estado, o que incluía precisas definições legais sobre sua função, pode dificultar a percepção de grandes variações no papel real dessa forma escolar no seu contexto local. Formar a elite por meio de uma educação intensivamente humanista foi apenas parte das funções de tais escolas. Generalizações históricas têm negligenciado tanto o fato de que muitos alunos abandonavam os estudos após poucos anos, quanto a diversidade de modelos existentes (escolas religiosas na França, escolas modernas na Alemanha, escolas particulares na GrãBretanha etc.). Pesquisas que procuram compreender o Ensino Secundário dentro de seu contexto urbano sociocultural têm apresentado resultados potencialmente mais consistentes.

A partir dessa observação, e com base em autores como Emile Durkheim, Anderson (2004) afirma que qualquer ideia de que a natureza do ensino secundário dependia de desenvolvimento social e econômico sempre enfrentou o problema de incongruência. Afinal, por que em uma sociedade moderna, capitalista, industrial persistiria uma educação de caráter humanista, aparentemente incorporando valores aristocráticos de modo tão forte? Por que as alternativas baseadas na ciência, introduzidas por muitas reformas governamentais iluministas e pela Revolução Francesa, nas escolas centrais de 1795 , se deram de modo tão reservado?

Segundo Anderson (2004), respostas a questões como essas foram tratadas por pesquisadores como Fritz Ringer, Detlef Muller, Hartmut Kaelble, Brian Simon e Lemore O'Boyle que, nos anos 1970 e 1980, como parte da chamada Nova História Social, produziram estudos que procuravam quantificar em grande escala dados referentes a matrículas, origens sociais dos alunos, mobilidade social, profissionalização e formação de elite.

Por meio dos trabalhos de Ringer, fundamentalmente, difundiram-se os conceitos de inclusão (quantas pessoas frequentavam a escola secundária?) e de progressividade (quão baixo na escala social chegava o atendimento dessa escola?). Ringer também colocou em circulação o conceito de segmentação, argumentando 
que, como a demanda pelo Ensino Secundário se expandiu na segunda metade do século XIX, essa demanda foi desviada para novos tipos inferiores de escola, permitindo que a função das antigas escolas de elite permanecesse intacta com mínimas concessões ao utilitarismo.

As constatações dos trabalhos daqueles autores, com foco privilegiado sobre o eixo Alemanha-França-Inglaterra, remetem ao fato de que mesmo em tais países (com forte tradição sobre o Ensino Secundário), o modelo era um quadro conceitual, financeira ou juridicamente imposto a uma realidade muito diversa, e que havia uma lacuna entre a retórica elitista da escola, sustentada principalmente pelo treinamento universitário dos professores, e seu papel social real que era mais diversificado. Diante disso, dois aspectos devem ser examinados: as fronteiras, ainda mutáveis, entre o ensino secundário e superior, bem como a diversidade de sistemas de ensino no início do século XIX.

De um lado, a remodelação das escolas secundárias geralmente está associada a uma redefinição da fronteira com as universidades, e esse movimento tomou corpo, em diferentes países, em algum momento entre os anos de 1850 e 1870: na Suécia, em 1852; no Piemonte, em 1857, mais tarde estendido para o novo reino da Itália; na Holanda, em 1876; na Suíça, na década de 1870. De outro, aqueles historiadores descobriram que os alunos cuja origem social seria de corte estritamente elitista poderia corresponder apenas a $20 \%$ das matrículas. A maior parte seria proveniente das famílias de artesãos, pequenos comerciantes, camponeses e funcionários públicos de baixo e médio escalão. Para esses grupos, o secundário oferecia uma possível mobilidade social.

Dois elementos foram muito comuns a vários países. Um é que escolas com taxas relativamente baixas de matrícula poderiam ser usados pelas famílias de artesãos, pequenos comerciantes, camponeses e funcionários públicos de baixo e médio escalão - sempre os grupos sociais mais inclinados a usar a educação como um instrumento de mobilidade social. O segundo é o que os pesquisadores chamaram de pirâmide etária, o modo pelo qual a frequência caía, abruptamente, a cada ano do curso, visto que muitos desses alunos encerravam os estudos o mais rápido possível para trabalhar em lojas, escritórios e empresas. Apenas aqueles cujo objetivo era adquirir alguma profissão ou entrar nas universidades concluíam o curso secundário.

Apesar das variações locais, junte-se aos elementos comuns mais um fato. Como as escolas secundárias tinham um papel social mais amplo - dada a sua maior ramificação e forma de acesso - do que a universidade, elas foram mais eficazes do que a última para criar um sentimento nacional homogêneo, especialmente onde as lealdades provinciais tiveram que ser superadas. E se o ensino secundário tinha esse papel nos Estados-nação, estabelecidos a partir dos anos 1870, foi igualmente fundamental para os planos das nações aspirantes. Isso porque uma nação em 
formação precisava de uma intelligentsia nacional, e a escola secundária acabou se tornando o locus de formação dos intelectuais de segundo escalão que eram a espinha dorsal de movimentos nacionalistas.

Em resumo, Anderson (2004) defende que o modelo da nova escola secundária, criado por volta de 1802 , se tornou um padrão adotado em momentos diferentes em diferentes países. As diferenças podem estar relacionadas a fatores políticos, como a formação do Estado e do nacionalismo, bem como a questões sociais. Para os governos, a função elitista do ensino secundário era o que importava, e isso foi o que dominou o discurso oficial e também justificou a negligência do ensino secundário para meninas.

Atualmente, as pesquisas mais frutíferas são aquelas que analisam o ensino secundário em seu contexto urbano, que procuram compreender os anseios das famílias em relação à escola e como elas realmente fizeram uso dessa instituição. A verdadeira cultura da escola secundária, diferente do currículo oficial, está na forma como a estrutura desse sistema foi afetada por questões de gênero, etnia e divisões religiosas e em como as escolas funcionavam para integrar as elites locais e regionais em culturas nacionais e (às vezes) lealdades supranacionais.

\section{Espaços de formação escolar da elite letrada sergipana}

Partilho do entendimento que a relação entre o Estado, a família e a escola apresentava suas próprias nuances no XIX, e que conflitos existiram até que a educação escolar, como a conhecemos, tornou-se o padrão. No caso dos professores aqui investigados, destacam-se os casos de educação doméstica, ou intrafamiliar (com parentes como professores) e em instituições fundadas ou dirigidas por outros membros dessa mesma elite letrada. Essas instituições já foram apresentadas aqui. Resta observar, ainda, aqueles que passaram por elas como alunos. Penso que é muito frutífero analisar esses espaços formativos para além da pura tarefa de ensinar conteúdos, mas também como espaço de distinção de um grupo, por sua vez de consolidação de uma identidade.

A instituição particular mais citada nas biografias aqui analisadas é o Parthenon Sergipense, fundado e dirigido por Ascendino Reis. No Parthenon estudou João Antônio Pereira Barreto (1876-1926). Filho do Major Odorico Antônio Pereira Barreto e Maria Petronila Barreto. Nascido na cidade de Estância, ainda criança mudou-se para 
Aracaju, onde fez os estudos primários e secundários na referida escola. Finda essa etapa, em 1887, partiu para a província da Bahia para trabalhar no comércio.

Mudou-se para São Paulo. Doente, voltou para Sergipe. Após um período como guarda-livros na cidade de Maruim, foi nomeado lente interino da cadeira de Escrituração Mercantil do Ateneu Sergipense, em 1896. O posto de efetivo da cadeira de História, assumido em outubro daquele ano, não durou mais de um mês, visto que sofreu acusação de ter sido nomeado sem o necessário concurso. Foi sócio do Gabinete de Leitura de Maruim, eleito seu presidente e orador oficial em dois mandatos (1895-1896), e do Instituto Histórico e Geográfico de Sergipe. Teve participação ativa na imprensa da época, publicando em vários periódicos.

Antônio Dias de Barros (1871-1928), filho de Manuel Dias de Barros Junior, foi aluno da mesma escola, mas teve uma trajetória de formação escolar bem distinta daquela do outro Antônio. Natural de Aracaju, vivenciou a experiência da educação doméstica em um primeiro momento. Com sua mãe, Maria Prisciliana de Carvalho, aprendeu os rudimentos da língua portuguesa. Depois, foi aluno das professoras Maria Damásio e Angélica Teles de Menezes, que, muito provavelmente, ministravam aulas em suas próprias casas.

Sua passagem pelo Parthenon foi breve, logo depois passou ao Ateneu Sergipense. Em 1886, mudou-se junto com a família para a Bahia e lá deu continuidade não só aos estudos, como também à peregrinação por várias instituições escolares. Para concluir os estudos das Humanidades, já bem adiantado em Aracaju, foi aluno nos colégios Manoel Florêncio, São Salvador, Sete de Setembro e no Liceu Baiano. Mesmo quando entrou no curso superior de Medicina, em 1889, não deixou de ser um tanto quanto nômade como aluno. Estudou na Faculdade de Medicina da Bahia até o oitavo ano de curso, depois deu prosseguimento na congênere do Rio de Janeiro, talvez seduzido pelos ares da capital da nação. Seja como for, recebeu grau de doutor em 1895.

Sua experiência como docente não foi em Sergipe, mas na Capital Federal. Lá, foi lente de Bacteriologia, em 1906. Cinco anos depois, lente da cadeira de Anatomia Microscópica e regente do curso de Anatomia e Fisiologia do Sistema Nervoso e de Sintaxe Portuguesa no Pedagogium. Apesar de seu afastamento da terra natal, foi Deputado Federal por seu Estado, entre 1912 e 1914, e sócio honorário do Instituto Histórico e Geográfico de Sergipe.

Outro aluno do Parthenon foi o laranjeirense, filho de Rufino Alves da Cruz Guimarães e Ignácia Maria d'Assunção Moreira Guimarães, Antônio Maria Moreira Guimarães. Antes de ser aluno dessa escola, fez as primeiras letras, muito provavelmente, na já referida modalidade doméstica. Em 1890, entrou na Escola Militar da Praia Vermelha, no Rio de Janeiro, para os estudos superiores. Todavia, não 
chegou a concluir o curso, pois em 1893 foi dispensado por ser considerado fisicamente incapaz para o serviço militar.

Uma vez na Capital Federal, e com a interrupção dos estudos, dedicou-se à ocupação docente - e muito. O grau de formação que havia atingido, apesar de incompleto, Ihe possibilitou trabalhar no Colégio Universitário Fluminense, no Colégio Abílio, no Colégio Antônio Teixeira, no Colégio Santana, na Escola Normal Livre e no Asilo São Francisco. Ainda foi, juntamente com o Barão Homem de Melo, Laudelino Freire e outros, fundador do Instituto Didático. A investida no ofício docente, possivelmente, Ihe proporcionou as condições para fazer o curso jurídico na Faculdade Livre de Direito do Rio de Janeiro, onde recebeu o grau de bacharel em 1902. Depois disso, dedicou-se à carreira jurídica, exercendo cargos em várias cidades do país.

Um último caso de ex-aluno do Parthenon. O filho do tenente-coronel Zephyrino Cardoso e Maria do Patrocínio de Aguiar Cardoso, e irmão de Fausto Cardoso, José Matheus de Aguiar Cardoso. Ele nasceu na propriedade da família, o engenho São Felix (em Divina Pastora) em 1864, e faleceu em Manaus, onde residiu boa parte da vida, em 1895. Sua passagem pela referida escola se deu quando realizou os estudos preparatórios para os exames ao curso superior. Não estudou apenas lá. Passou também por escolas em Maruim e no 07 de Setembro, na Bahia.

Em 1879 estava matriculado na Faculdade de Direito de Recife, de onde saiu bacharel, cinco anos depois. Sua vida profissional foi dedicada, quase que exclusivamente, à carreira jurídica. Formado, atuou como promotor nos municípios de Riachuelo, Boquim e Lagarto. Em 1887, mudou-se para o Amazonas, ainda na carreira jurídica. Lá foi também diretor da Biblioteca Pública e teve sua passagem pela ocupação docente. Foi lente de Pedagogia da Escola Normal, depois catedrático, por concurso, de Sociologia e Moral no Instituto Nacional Superior. Passou pouco tempo nessa ocupação. Em 1891, já estava no Rio de Janeiro, de volta à carreira jurídica e às colaborações com a imprensa da época. Chegou a ser juiz municipal, mas regressou ao Amazonas, por questões de saúde, em 1894, e foi reintegrado à cadeira docente que ocupava quando saiu. Pouco depois, faleceu.

O Parthenon destaca-se, então, como uma instituição escolar da qual saíram formados, total ou parcialmente, sujeitos pertencentes ao perfil constituinte da elite letrada sergipana que atuaram aqui e em outras partes do Brasil. Pode-se inferir que a matrícula dos filhos nessa escola representava a busca das famílias não apenas por uma boa formação do ponto de vista dos conteúdos escolares, mas também dos hábitos, dos modos, dos projetos de vida. Uma convivência que propiciasse a formação de uma identidade, que mantivesse a unicidade da identidade desse grupo, ou a entrada nele. 
Outros espaços, fundados ou dirigidos por intelectuais sergipanos, também figuram no cenário das instituições de cujos bancos escolares saíram os sujeitos analisados nesta pesquisa. Veja-se o caso do Ginásio Sergipense, dirigido por Alfredo Montes ${ }^{4}$. De lá, saíram aptos a tentar uma vaga em um dos cursos superiores existentes no país, ou adentrar em um dos ramos de carreira do funcionalismo público (ou ambas as coisas), intelectuais como Alfredo Cabral.

Nascido em Aracaju, no ano de 1887, filho de Francisco Felix Cabral e Adelaide Passos Cabral, terminou o curso de Humanidades no Ateneu Sergipense, após tê-lo iniciado no colégio dirigido por Alfredo Montes (que também era professor do Ateneu). Em 1907, formou-se bacharel pela Faculdade de Direito de Recife e começou a atuar na promotoria - primeiro em Estância, depois Laranjeiras e por fim em Maruim. Das possibilidades ao alcance de um intelectual sergipano naquela época, parece que o ofício docente se apresentou mais vantajoso para ele. Em 1911, assumiu a cadeira de História Universal do Ateneu Sergipense, de onde fora aluno. Cinco anos depois foi transferido para a cadeira de Educação Moral e Cívica, Noções de Sociologia e Direito Usual da Escola Normal.

Outro egresso do Ginásio Sergipense, que teve uma trajetória similar à de Alfredo Cabral, é o filho de Benjamin Francisco Brandão e Maria Philonilla Brandão, Josafá da Silveira Brandão. Natural de Estância, nasceu em 1880. Foi aluno interno da referida instituição escolar, depois do que entrou no curso de Medicina da Bahia, e de lá saiu formado em 1902. Desde logo se envolveu nas questões educacionais. Foi Inspetor do Ensino na cidade natal e, já na capital de Sergipe, em 1912, foi nomeado Diretor do Ateneu Sergipense, cargo que ocupou nos quatro anos seguintes. Dividiu sua atividade docente entre o Ateneu e a Escola Normal, onde regeu cadeira de Física e Química aplicada à vida prática.

A criação do Atheneu Sergipense no início da década de 1870 possibilitou a concentração de intelectuais já reconhecidos na sociedade sergipana como elite do corpo docente disponível na província. Eram homens que já detinham longa trajetória nesse oficio e que, em alguns casos, já haviam administrado estabelecimentos educacionais. Apesar de ser uma instituição pública, ser aluno do Atheneu implicava em altos custos, o que tornava o acesso restritivo, sem dúvida, à maioria da população sergipana. O Atheneu, embora não fosse uma escola particular, era um locus de formação de uma elite letrada e por ele passaram alguns dos biografados aqui analisados. Foi possível identificar, com exatidão, alguns exemplos.

O Atheneu foi um local de referência mesmo para aqueles que não fizeram o percurso de estudos completos, como é o caso de Antônio Joaquim Viana. Filho de

\footnotetext{
${ }^{4}$ Para mais informações acerca de Alfredo Montes, ver Amorim (2009): A trajetória de Alfredo Montes, 1848-1906: representações da configuração do trabalho docente no ensino secundário em Sergipe. Aracaju: Fundação Oviedo Teixeira; São Cristóvão: Editora da UFS, 2009.
} 
José Joaquim de Santa Anna e Maria Gratulina de Santa Anna, nasceu no Aracaju, em 1882. Sua passagem pelo Atheneu foi incompleta, visto que concluiu os estudos de Humanidades no Rio de Janeiro e lá mesmo iniciou o curso da Faculdade de Medicina. Não chegou a concluir esses estudos, segundo consta, por falta de recursos financeiros. A docência parece ter sido a alternativa encontrada por Antônio Joaquim Viana para garantir sua subsistência e sua colocação social. Iniciou-se no oficio, fundando o Externato Viana; depois, foi lente catedrático de Português da Escola Normal da Capital Federal.

Cleóbulo Amazonas Duarte também teve uma passagem pelo Atheneu em meio à sua trajetória de formação. Nascido em 1898, na capital sergipana, filho de Antônio Pedro Duarte e Irinéa Amazonas Duarte, mudou-se, ainda muito criança, com sua mãe para Maruim; com ela estudou as primeiras letras, como era bastante comum à época. Em 1909, matriculou-se no Ateneu, onde estudou por cinco anos, terminando essa etapa escolar em outros colégios.

Mudou-se, depois, para a cidade de Santos, litoral de São Paulo, e, logo em seguida, para o Rio de Janeiro, onde se matriculou no curso de Farmácia. Não concluiu, abandonou Farmácia para fazer o curso de Direito, no qual se formou em 1921. Foi no Rio de Janeiro que vivenciou suas primeiras experiências como professor, atuando nos colégios Lessa, Silvio Leite e no Ginásio 28 de Setembro, do qual foi secretário geral e professor de História Universal. No mesmo ano em que se diplomou, voltou para Santos e exerceu, além da docência, cargo de vice-diretor de uma escola. Depois de um tempo, passou a exercer a advocacia, possivelmente em concomitância com a vida de professor, e foi colaborador em vários jornais da época, até falecer em 1979.

Enquanto esses dois casos ilustram situações em que o Ateneu foi um lugar de passagem, há outros casos em que se percebe que essa escola foi um espaço de formação completa de alguns intelectuais do período aqui destacado. Um desses foi o filho de Estevão Coelho e Jesuína Sampaio Coelho, que nasceu em Aracaju, em 1886. Trata-se de Edgard Coelho. No Ateneu Sergipense cursou o Secundário, entre os anos de 1903 a 1907. Depois, entrou na Faculdade Livre de Direito da Bahia, de onde saiu bacharel no final de 1911. Diplomado, foi procurador fiscal do Tesouro do Estado. Em 1913, assumiu o lugar de Inspetor Geral do Ensino. Três anos depois foi nomeado Diretor do Grupo Escolar General Siqueira e tomou posse como professor catedrático da cadeira de Educação Moral e Cívica, Noções de Sociologia e Direito da Escola Normal de Aracaju.

Essas trajetórias reforçam o entendimento de como as instituições escolares, sejam os colégios particulares, seja o Ateneu Sergipense, foram locus de reprodução da elite sergipana. Elite da qual saíram sujeitos que se dedicaram ao ofício docente. Sujeitos que estabeleceram, a partir de si, a representação do bom professor. Professores que fundaram e dirigiram escolas, que depois constituíram o quadro 
docente da única escola de Ensino Secundário mantida pelo poder público e que formaram novos quadros para a vida pública sergipana. Definiram, a partir de si, o perfil do ser docente, do ponto de vista da formação e da constituição do habitus civilizado.

\section{Referências}

AMORIM, S.S. A trajetória de Alfredo Montes, 1848-1906: representações da configuração do trabalho docente no ensino secundário em Sergipe. Aracaju: Fundação Oviedo Teixeira; São Cristóvão: Editora da UFS, 2009.

ANDERSON, R. The idea of the Secondary School in nineteenth century Europe. Paedagogica Historica, S/L, v. 40, n.1-2, p.93-106, abr. 2004.

AZEVEDO, F. A cultura brasileira. Tomo III - A transmissão da cultura. 5ed. São Paulo: Melhoramentos; Brasília: INL, 1976.

CHERVEL, A. Quando surgiu o Ensino "Secundário"?. Revista da Faculdade de Educação, São Paulo, v. 18, n.1, p.99-112, jan.-jun. 1992.

HAIDAR, M.L.M. O Ensino Secundário no Brasil Império. 2ed. São Paulo: EDUSP, 2008.

NUNES, M.T. História da educação em Sergipe. Rio de Janeiro: Paz e Terra; Aracaju: Secretaria da Educação e Cultura do Estado de Sergipe/UFS, 1984. (Coleção Educação e Comunicação, v. 13).

PEREIRA, J.B.B. A escola secundária numa sociedade em mudança interpretação socioantropológica de uma experiência administrativa. São Paulo: Pioneira, 1969.

SILVA, E.A.V. da. A formação intelectual da elite sergipana (1822-1889). 2004. 92f. Dissertação (Mestrado em Educação) - Universidade Federal de Sergipe. São Cristóvão, 2004. 